\title{
PESAN DAKWAH DAN GAYA BAHASA PADA LIRIK LAGU “SEBUJUR BANGKAI” RHOMA IRAMA
}

\author{
Mega Cynthia \\ STID Al-Hadid, Surabaya \\ megacynthia75@gmail.com
}

\begin{abstract}
Abstrak: Salah satu cara penyampaian pesan dakwah adalah melalui lagu. Lagu bersifat mudah dipahami dan menghibur sehingga lebih melekat bagi mad'uw. Hal tersebut didukung penggunaan gaya bahasa yang tepat pada liriknya. Dewasa ini mulai banyak dai yang menggunakan lagu sebagai metode dakwahnya. Namun tidak semua menggunakan gaya bahasa yang tepat, akibatnya pesan dakwahnya hanya sepintas lalu pada benak mad'uw. Salah satu lagu sarat pesan dakwah adalah "Sebujur Bangkai" yang diciptakan Rhoma Irama. Lirik yang bergenre musik dangdut itu sampai dengan saat ini sudah didengar sebanyak 15.475 .050 kali di kanal Youtube label musik Falcon. Sangat jarang dijumpai lagu bergenre dangdut namun kuat nilai-nilai agamanya hingga diterima kalangan luas dan bertahan lintas generasi. Untuk itu lagu tersebut menarik dikaji dari sudut pandang dakwah. Adapun fokus tujuan pada kajian ini adalah untuk mendeskripsikan penggunaan gaya bahasa dan pesan dakwah yang digunakan pada lagu tersebut. Studi ini menggunakan metode analisis teks. Pada lirik lagu tersebut terdapat penggunaan gaya bahasa yang bervariasi mulai dari asonansi, aliterasi, personifikasi, eufemisme, disfemisme, perifrasa, metafora, satire, sinekdoke pars pro toto, hiperbol, dan polisindenton. Lalu adanya penggunaan pesan dakwah tarhib dan indzar, tadzkir dan tanbih, dan taklim dan tarbiyah qoshos dan riwayar pada lirik lagu.

Kata kunci: Lirik Lagu, Gaya Bahasa, Pesan Dakwah, Lirik Lagu "Sebujur Bangkai" Karya Rhoma Irama
\end{abstract}

\begin{abstract}
One of the ways to deliver a da'wah message is through a song. A Song is understandable and entertaining so that it attaches closely to mad'uw. It is supported with figurative language usage in the lyrics. Recently many dai start to use a song as a da'wah method. However, not all of them use the right figurative language. As a result, the da'wah message is only fleeting in mad'uw's mind. One of the songs full of da'wah messages is "Sebujur Bangkai" by Rhoma Irama. Until now, the lyrics have been heard 15,475,050 times on Youtube channel of the Falcon music label. It is very rare to find such a dangdut song with strong religious values which is widely accepted and lasts for generations. Therefore, focus of this study is to describe figurative languages and da'wah messages used in the song. This study uses text analysis method. In the lyrics, there are uses of various figurative languages ranging from assonance, alliteration, personification, euphemism, dysphemism, periphrasis, metaphor, satire, synecdoche pars pro toto, hyperbole, and polysyndenton. Then there are da'wah message usages of Tarhib and indzar, Tadzkir and tanbih, and Taklim and Tarbiyah, Qoshos and Riwayar.

Key words: Song Lyrics, Figurative language, Da'wah message, Song Lyrics "Sebujur Bangkai" from Rhoma Irama
\end{abstract}




\section{Pendahuluan}

Dakwah menurut Moh. Ali Aziz dalam bukunya yang berjudul Ilmu dakwah adalah proses kegiatan yang dilakukan untuk meningkatkan keyakinan dan perubahan perilaku yang lebih baik lagi sesuai dengan ajaran Islam. ${ }^{1}$ Pada dakwah terdapat unsur pesan dakwah. Pesan dakwah adalah ide, gagasan tentang nilai atau ajaran Islam yang disampaikan untuk membuat perubahan yang lebih baik di masyarakat. ${ }^{2}$ Agar dakwah bisa terus eksis maka diperlukan metode yang tepat. Perkembangan zaman, budaya, maupun kesukaan masyarakat menjadi pertimbangan untuk menggunakan metode dakwah yang sesuai. Dalam hal ini lagu yang bernuansa religi dapat menjadi metode dakwah yang efektif. Baik dari genre pop, nasyid, maupun dangdut. Pelaku atau aktivis yang melakukan dakwah pun akhirnya bisa meluas bukan hanya yang berstatus dai tetapi juga musisi yang tertarik untuk menyebarkan nilai Islam lewat lagu yang diciptakan. Selain itu mudah untuk memengaruhi emosi/perasaan pendengar dari kekuatan sebuah lirik lagu. Dakwah yang biasanya cenderung monoton menjadi lebih menyenangkan, tidak membosankan untuk didengar karena dapat berkolaborasi dengan seni dan hiburan. Dalam sejarah dakwah di Indonesia, Walisongo juga menggunakan lagu sebagai metode dakwah

\footnotetext{
1. Moh. Ali Aziz, Ilmu Dakwah (Jakarta: Kencana Prenada Media, 2004), 19.

2 M. Quraish Shihab, "Membumikan" Al-Qur'an, Fungsi dan Peran Wahyu Dalam Kehidupan Masyarakat (Bandung: Mizan, 1993), 194.

3 Abdus Salam, "Mengkaji Syair Lir-Ilir Karya Sunan Kalijaga," alif.id, diakses 25 Juli 2020 https://alif.id/read/abdus-salam/mengkaji-syair-lirilir-karya-sunan-kalijaga-b221759p/

4 Restiawan Permana, "Strategi Komunikasi Dakwah Band Wali dalam Lagu Cari Berkah," Jurnal Komunikasi Islam vol. 03, no. 01 (2013): 121-136.
}

di masanya. Salah satu lagunya berjudul Lirilir berpesan agar senantiasa membangun keimanan, menghindari kemaksiatan, membangun ketakwaan, dan menjaga keimanan. ${ }^{3}$

Syair atau lirik lagu menjadi hal yang penting dalam lagu. Sebab dalam syair tersebut terdapat pesan dakwah yang hendak disampaikan kepada pendengar atau mad'uw. Pesan yang ada dalam syair lagu dakwah berisi tentang nilai-nilai atau ajaran Islam. ${ }^{4}$ Tujuannya untuk membangun, memperbaiki, dan merawat agar masyarakat menjadi lebih baik dan tidak menyekutukan Allah. ${ }^{5}$ Oleh sebab itu dalam sebuah syair dakwah harus berisikan ajaran nilai, etika yang benar dalam Islam Selain itu, tidak membuat pendengar syair termotivasi untuk melakukan keburukan atau kemungkaran tetapi justru termotivasi bergerak ke arah kebaikan. Kemudian pesan yang disampaikannya tidak boleh ada unsur-unsur kemaksiatan yang bertentangan dengan syariat Islam. ${ }^{6}$

Kumpulan kata-kata yang indah dan ekspresi rasa sebagai wujud empati pengarang lagu terhadap kondisi sosial menjadi komposisi dalam lirik lagu. ${ }^{7}$ Komposisi kata-kata yang indah pada lirik lagu merupakan wujud penggunaan gaya bahasa. ${ }^{8}$ Dengan penggunaan gaya bahasa dalam syair lagu memudahkan pendengar

\footnotetext{
5 Jum'ah Amin Abdul Aziz, Fiqih Dakwah: Prinsip Dan Kaidah Asasi Dakwah Islam (Surabaya: Era Intermedia, 2005), 29.

${ }^{6}$ Ali Anwar Yusuf, Islam Dan Sains Modern: Sentuhan Islam Terhadap Berbagai Disiplin IImu (Bandung: Pustaka Setia, 2006), 273-277.

7 Ibid.

${ }^{8}$ Siswono S.S., Teori dan Praktik: Diksi, Gaya Bahasa, dan Pencitraan (Yogyakarta: Deepublish, 2012), 26.
} 
untuk menginternalisasi pesan yang disampaikan dan sampai pada sisi afeksi sebagaimana pendapat dari Imam Al Ghazali dalam Dimyati pada kitabnya yang berjudul "Ihya Ulumud Din". ${ }^{9}$ Selain itu bagi Gorys Keraf makin banyak referensi pilihan gaya bahasa yang digunakan maka akan membuat pesan menjadi menarik dan mudah untuk diterima oleh komunikan. ${ }^{10}$ Begitu juga dengan penggunaan gaya bahasa dalam syair lagu dapat membuat pesan menjadi menarik dan mudah untuk diterima oleh mad'uw. Dampak lain dari penggunaan gaya bahasa selain bisa memunculkan komunikasi yang efektif bisa juga memunculkan sebuah penilaian terhadap seorang dai. Saat seorang dai mampu menggunakan gaya bahasa yang baik, dan sesuai dengan mad'uw-nya dalam syair lagu maka mad'uw dapat memberikan penilaian positif terhadap dai. Begitupun sebaliknya, saat seorang dai tidak mampu menggunakan gaya bahasa yang baik dan sesuai dengan mad'uwnya maka mereka pun akan memberikan penilaian negatif terhadap dai. Gorys Keraf menyatakan bahwa, "Semakin baik gaya bahasanya, semakin baik pula penilaian orang terhadapnya; semakin buruk gaya bahasa seseorang, semakin buruk pula penilaian diberikan padanya." ${ }^{11}$ Jadi penilaian komunikan terhadap dai tidak hanya dari penampilan ataupun isi pesannya tapi bisa juga dari faktor gaya bahasa yang digunakan oleh dai. Hal ini penting menjadi perhatian

\footnotetext{
9. Farid Dimyati, "Kekuatan Musik dalam Dakwah Islam," nuonline, diakses 12 Juli 2019. www.nu.or.id/post/read/78651/kekuatan-musikdalam-dakwah-islam.

10 Gorys Keraf, Diksi dan Gaya Bahasa (Jakarta: Gramedia Pustaka Utama, 1984), 21-23.

11. Ibid., 113.

12 Yesaya Whisnu Wardana, "Perkembangan Musik Dangdut dan Sensualitas Goyangan Para Biduannya,"
}

bagi seorang dai saat hendak melakukan dakwah kepada mad'uw lewat syair lagu.

Dangdut pada awal kemunculannya berfungsi sebagai media dakwah sebagaimana yang diawali oleh Rhoma Irama di dunia musik Indonesia. Akan tetapi fungsi dari musik itu mulai bergeser di tahun 80-an akibat banyaknya kemunculan penyanyi wanita dengan goyangannya dan lirik lagu yang banyak menggambarkan perasaan istri dengan pesan khas kegagalan romansa berumah tangganya. ${ }^{12}$ Selain itu menurut Frederick dalam bukunya yang berjudul Rhoma Irama and the Dangdut Style: Aspects of Contemporary Indonesian Populer Culture (1982) sebagaimana dikutip oleh Wardana, bahwa pesan dangdut dinilai masih berbau pesan yang sensual, tidak sopan, kampungan. ${ }^{13}$ Senada dengan hal itu kini musik dangdut masih diidentikan dengan pesan sensualitas. ${ }^{14}$

Kemudian masalah lainnya adalah masih ada dai yang menggunakan gaya bahasa yang tidak tepat saat menyampaikan pesan dakwah kepada mad'uw. Pada 15 Juli 2017 seorang penceramah di program Islam Itu Indah Trans TV telah menuai banyak protes dari publik. Penceramah tersebut ialah Ustaz Syamsuddin Nur Makka alias Ustaz Syam. Berikut penggalan ceramahnya, "Salah satu nikmat yang ada dalam surga adalah pesta seks". Ungkapan pesta seks tersebut menuai respon negatif dari publik bahkan peringatan dari KPI. Pernyataannya

Compusiciannews.com, diakses Juli, 2020. https://compusiciannews.com/2020/07/08/perkemb angan-musik-dangdut-dan-sensualitas-goyanganpara-biduannya/

13 Ibid.

14 Nuran Wibisono, "Dangdut Koplo, Puncak Evolusi Dangdut," tirto.id, diakses tanggal 14 Agustus, 2020. https://tirto.id/dangdut-koplo-puncak-evolusidangdut-cACW. 
tersebut sebenarnya hanya untuk menjelaskan kebahagiaan hidup di surga bersama para bidadari namun kesalahan penyebutan itulah yang memberikan feedback negatif dari para pendengar dan penonton Indonesia. ${ }^{15}$ Oleh sebab itu penting bagi dai untuk menguasai dan menggunakan gaya bahasa yang tepat dalam menyampaikan dakwah. Khususnya ketika menjadikan lagu sebagai metode dalam penyampaian pesan dakwahnya. Dari pemaparan tersebut penulis tertarik dengan lirik lagu dari H. Rhoma Irama selaku King Of Dangdut yang berjudul Sebujur Bangkai. Lagu yang bergenre dangdut tersebut dikeluarkan pada tahun 1983 dan dimunculkan kembali di tahun 2010. ${ }^{16}$ Menurut data yang ada di kanal YouTube label musik Falcon, lagu Sebujur Bangkai telah didengarkan oleh publik sebanyak 15.475.050 kali. ${ }^{17}$ Data tersebut menunjukkan publik telah banyak yang mendengarkan dan menikmati lagu tersebut. Kemudian lirik lagunya juga bertemakan dakwah walaupun musiknya bergenre dangdut. ${ }^{18}$ Terbukti dari pesan yang disampaikan mengingatkan kepada kematian dan situasi di alam kubur yang begitu mencekam. ${ }^{19}$ Jika melihat komentar di akun YouTube Falcon, netizen cenderung berkomentar positif dan merasa

\footnotetext{
15 Nur Qolbi dan S. Dian Adryanto, "Ustadz Syam Minta Maaf ke MUI, Ceramahnya Diprotes Publik," TEMPO.CO, diakses Agustus, 2017.

https://nasional.tempo.co/read/893193/ustadzsyam-minta-maaf-ke-mui-ceramahnya-diprotespublik.

16 Sulaiman Harahap, "Rhoma Irama: Sang Penghulu Mempelai Dangdut dan Dakwah," Republika.co.id, diakses tanggal 04 Juli, 2019, https://www.republika.co.id/berita/nasional/umum/ 15/08/05/senggang/musik/12/04/16/m2kji3-rhomairama-sang-penghulu-mempelai-dangdut-dandakwah.

17 Sebujur Bangkai," Video Youtube, 4:08, dikirim oleh “Falcon," Juni 17, 2013. https://www.youtube.com/watch?v=PdXIjK7LRKU.
}

tersadarkan dari pesan yang disampaikan. ${ }^{20}$ Begitu juga menurut Rahmat, Simatupang, dan Albertus, lirik Sebujur Bangkai terdapat banyak sekali pengajaran nilai Islamnya. ${ }^{21}$ Penjelasan tersebut menunjukkan adanya penggunaan gaya bahasa dan pesan dakwah pada lirik lagu Sebujur Bangkai.

Tulisan ini bertujuan untuk mendeskripsikan gaya bahasa dan pesan dakwah yang digunakan pada lirik lagu Sebujur Bangkai. Fokusnya adalah analisis penggunaan gaya bahasa secara langsung dan tidak langsungnya makna, kemudian menganalisis kekhasan setiap penggunaan jenis gaya bahasa pada lirik, dan mengkaji pesan dakwah yang disampaikan dalam lirik lagu. Metodologi yang digunakan yaitu analisis teks. Sumber data diambil dari data sekunder yaitu sonora.id. Kajian ini menggunakan uji peningkatan ketekunan. Penulis melakukan analisis ulang sebanyak empat kali secara lebih teliti dan berkelanjutan terhadap data yang ada untuk membuktikan keabsahan hasil analisis yang sudah didapat. ${ }^{22}$

Kajian mengenai pesan dakwah dan gaya bahasa sudah banyak dilakukan dalam beberapa kajian jurnal dan skripsi. Seperti Pesan Dakwah Dalam Lagu "Bila Tiba" oleh

\footnotetext{
18 Moeflich Hasbullah, Islam Dan Transformasi Masyarakat Nusantara (Depok: Kencana Prenada Media, 2017), 171.

19 Khairul Umam dan Kamalludin, "Analisis Nilai-Nilai Pendidikan Islam Dalam Lirik Lagu Rhoma Irama," Fikrah: Journal of Islamic Education, vol. 02, no. 1 (2018): 17.

$20 \mathrm{lbid}$.

21 Sujud Puji Nur Rahmat, G.R. Lono Lastoto Simatupang, dan A. Harsawibawa, "Musik Metal dan Nilai Religius Islam Tinjauan Estetika Musik Bermuatan Islami dalam Penampilan Purgatory," Resital Vol. 18, no. 03 (2017): 134.

22 Sugiyono, Metode Penelitian Kuantitatif, Kualitatif, dan R\&D (Bandung: Alfabeta, 2014), 270-272.
} 
Bagus Sujatmiko dan Ropingi el Ishaq, ${ }^{23}$ Analisis Pesan-Pesan Dakwah Dalam SyairSyair Lagu Opick oleh Yantos, ${ }^{24}$ dan Pesan Dakwah Dalam Lirik Lagu Menyambut Lebaran Karya Pendhoza oleh Ferdian Achsani dan Siti Aminah Nur Laila. ${ }^{25}$ Studi pada bidang gaya bahasa di antaranya: Gaya Bahasa Dalam Syair "Al-i'tiraf" Karya Abu Nuwas: Sebuah Analisis Stilistik, oleh Hanif Fathoni, ${ }^{26}$ dan Gaya Bahasa K.H. Zainuddin M.Z. Dalam Ceramah Isra Mikraj Di Tanggerang Selatan oleh Eka Anjani. ${ }^{27}$ Berdasarkan data yang ada, kajian mengenai pesan dakwah dan gaya bahasa pada lirik lagu Sebujur Bangkai belum pernah dikaji sebelumnya. Perbedaan studi ini dengan studi sebelumnya di antaranya: tidak mengkaji pesan dakwah berdasarkan semiotik nada dan liriknya dan bukan hendak membandingkan pesan dakwah antar lirik lagu. Bukan pula untuk menganalisis gaya bahasa langsung tidaknya makna pada ceramah dan fungsinya, ataupun hendak mencari makna emotif. Tujuan penulis yaitu untuk menemukan penggunaan pesan dakwah dan gaya bahasa berdasarkan langsung dan tidak langsungnya makna pada lirik lagu Sebujur Bangkai. Dengan begitu kajian mengenai pesan dakwah dan gaya bahasa pada lirik lagu Sebujur Bangkai merupakan

23 Bagus Sujatmiko dan Ropingi el Ishaq, "Pesan Dakwah Dalam Lagu "Bila Tiba,"Jurnal Komunika vol. 9, no. 02 (2015): 183.

${ }^{24}$ Yantos, "Analisis Pesan-Pesan Dakwah Dalam SyairSyair Lagu Opick," Jurnal Dakwah Risalah vol. 24, no. 2 (2013): 17.

${ }^{25}$ Ferdian Achsani dan Siti Aminah Nur Laila, "Pesan Dakwah Dalam Lirik Lagu Menyambut Lebaran Karya Pendhoza," Nalar: Jurnal Peradaban dan Pemikiran Islam vol. 3, no. 2 (2019): 126.

${ }^{26}$ Hanif Fathoni, "Gaya Bahasa Dalam Syair "Al-i'tiraf" Karya Abu Nuwas: Sebuah Analisis Stilistik," Jurnal AtTa'dib vol. 7, no.2 (2012): 209.

27 Eka Anjani, "Gaya Bahasa K.H. Zainuddin M.Z. Dalam Ceramah Isra Mikraj di Tanggerang Selatan." kajian yang baru. Manfaat adanya kajian ini yaitu dapat memberikan tambahan pengetahuan pada penggunaan gaya bahasa langsung dan tidak langsungnya makna. Selain itu dapat mengetahui pesan dakwah yang ada dalam lirik lagu Sebujur Bangkai, dan menjadi inspirasi untuk menggunakan berbagai varian gaya bahasa pada pesan dakwah sehingga dakwah tetap bisa tersampaikan walau menggunakan lirik lagu.

\section{Pesan Dakwah}

Pesan dakwah adalah gagasan ajaran Islam yang hendak disampaikan oleh dai kepada mad'uw-nya. Pesan dakwah adalah suatu hal yang disampaikan berupa nilai Islam yang ada di Al-Qur'an dan sunah rasul. ${ }^{28}$ Kemudian menurut Endang, sebagaimana yang ada dalam Q.S. Al-Ahzab ayat 39 merupakan pesan yang berisikan nilai hubungan antara manusia dengan tuhan, manusia dengan sesamanya, dan keseimbangan di antara keduanya. ${ }^{29}$

Bisa dikatakan bahwa pesan dakwah merupakan bahan yang disampaikan dalam ceramah maupun dakwah lainnya. ${ }^{30}$

Pada pesan, selain terdapat gagasan, ada juga tujuan, simbol yang digunakan untuk

Inteleksia: Jurnal Pengembangan Ilmu Dakwah vol. 01, no. 1 (2019):121.

28 Faizatun Nadzifah, "Pesan Dakwah Dosen Dakwah STAIN Kudus dalam Surat Kabar Harian Radar Kudus," AT-TABSYIR: Jurnal Komunikasi Penyiaran Islam vol. 01, no. 1 (2013): 113.

${ }^{29}$ Endang Islamawati, "Ekspresi Pesan Dakwah Dalam Syair-Syair Lagu Jefri Al-Bukhori (Analisis Terhadap Album 'Lahir Kembali')," (Skripsi, Institut Agama Islam Negeri Walisongo Semarang, 2008), Hal. 25.

30 Iftitah Jafar dan Mudzhira Nur Amrullah, "BentukBentuk Pesan Dakwah Dalam Kajian Al-Qur'an," Jurnal Komunikasi Islam vol. 08, no. 1 (2018): 43. 
menyampaikan pesannya, kemudian organisasi pesan. Simbol dalam pesan dakwah terdiri dari bahasa, gambar, visual, dan sebagainya. Salah satu keberhasilan dalam komunikasi dakwah adalah adanya pemilihan bahasa yang tepat baik diksi maupun gaya bahasa. Lewat bahasalah dai dapat menyampaikan gagasan pikiran, perasaan, fakta, dan opini. ${ }^{31}$

Dalam penulisan kali ini, penulis hanya mendalami pesan dakwah pada lirik lagu Sebujur Bangkai dan penggunaan gaya bahasa langsung dan tidak langsungnya makna dan tidak menganalisis bagian diksi pada lirik lagu.

\section{Jenis Pesan Dakwah}

Jenis pesan dakwah menurut A. Hajmy dalam Islamawati dibagi menjadi enam jenis sebagai berikut: (1) Taklim dan Tarbiyah merupakan gaya penyampaian dakwah dengan mendidik agar memiliki keimanan dan muamalah yang sesuai dengan nilainilai Islam; (2) Tadzkir dan Tanbih merupakan penyampaian dakwah dengan cara mengingatkan kembali akan nilai-nilai pengetahuan yang dimiliki dan diamalkan; (3) Targhib dan Tabsyir merupakan penyampaian dakwah dengan menyampaikan hal yang menyenangkan atau berita bahagia baik berupa pahala, maupun hal yang menyenangkan lainnya.

Tarhib dan Indzar yaitu menyampaikan hal yang menakutkan, menyedihkan, maupun siksaan; (4) Qoshos dan Riwayar adalah menyampaikan cerita sejarah; (5) Amar dan Nahi merupakan penyampaian dakwah yang berisi perintah, larangan, dan

31 Ibid.

32 Islamawati, "Ekspresi Pesan Dakwah Dalam SyairSyair Lagu Jefri Al-Bukhori" 10-11.

33 Keraf, Diksi dan Gaya Bahasa, 113. ancaman yang akan didapatkan saat melakukan pelanggaran. ${ }^{32}$

\section{Gaya Bahasa Berdasarkan Langsung Tidaknya Makna}

Gaya Bahasa menurut Gorys Keraf yaitu adanya penggunaan kata, frasa, klausa, kalimat, dan nada yang tersirat dalam sebuah wacana. ${ }^{33}$ Tarigan berpendapat pula bahwa tiap bahasa yang digunakan untuk mempersuasif saat berkomunikasi merupakan gaya bahasa. $^{34}$ Larousse menyatakan, "Le style est maniere particuliere d'exprimer sa pensee, ses emotions, ses sentiments." Bagi Larouse penggunaan gaya bahasa merupakan wujud dari pikiran, emosi, dan perasaan seseorang yang disampaikan. Hal ini menunjukkan bahwa selama ini gaya bahasa menjadi sarana keindahan bagi penyair untuk menarik perhatian pendengar hingga mencapai kesamaan pikiran, emosi, perasaan. ${ }^{35}$

Gaya bahasa memiliki beberapa jenis mulai dari gaya bahasa berdasarkan pilihan kata, struktur kalimat, langsung dan tidak langsungnya makna, dan nada. ${ }^{36}$ Pada tulisan ini berfokus pada analisis gaya bahasa berdasarkan langsung dan tidak langsungnya makna untuk mendalami kekhasan dan pesan dakwah pada lirik lagu. Tidak menganalisis gaya bahasa berdasarkan nada karena menganalisis lirik lagu bukan lagunya.

Gaya bahasa langsung tidaknya makna merupakan gaya bahasa yang mengacu

\footnotetext{
34 Henry Guntur Tarigan, Pengajaran Gaya Bahasa

(Bandung: Angkasa, 2013), 04.

$35 \mathrm{lbid}$.

${ }^{36} \mathrm{lbid}$.
} 
pada ada atau tidaknya penyimpangan makna dari bahasa yang digunakan. ${ }^{37}$ Gaya bahasa ini dibagi menjadi dua yaitu retorik dan kiasan. Gaya bahasa retorik yaitu gaya bahasa yang memberi efek tertentu pada komunikan dan maknanya tidak terlalu jauh dari makna yang sesungguhnya. ${ }^{38}$ Macammacam retorik yaitu aliterasi, asonansi, apofasis, anastrof, polisindenton, kiasmus, elipsis, eufemisme, litotes, histeron proteron, pleonasme dan tautologi, perifrasa, prolepsis, erotesis, silepsis, koreksio, hiperbol, paradoks, dan oksimoron.

Gaya bahasa aliterasi merupakan perulangan bunyi konsonan yang sama digunakan sebagai penekanan atau memberi efek keindahan. Contoh: Sayang segala ${ }^{39}$ Gaya bahasa hiperbol merupakan ungkapan yang berlebihan yang tidak sesuai dengan realitanya. ${ }^{40}$ Menurut Moeliono dalam Tarigan yaitu ungkapan melebihkan ukuran, jumlah, dan sifat. ${ }^{41}$ Contohnya adalah tabungannya berjuta-juta, emasnya, berkilo-kilo, sawahnya berhektar-hektar (dia orang kaya). ${ }^{42}$ Gaya bahasa perifrasa merupakan penggunaan banyak kata yang bisa diganti dengan satu kata. ${ }^{43}$ Contohnya yaitu saya menerima segala saran, petuah, petunjuk yang sangat berharga dari Bapak Lurah (nasihat). ${ }^{44}$

Gaya bahasa eufemisme merupakan penggunaan ungkapan pengganti yang tidak menyakiti hati, ataupun merugikan. ${ }^{45}$ Menurut Allan dan Buridge dalam

37 Ibid., 129.

$38 \mathrm{lbid}$.

39. Keraf, Diksi dan Gaya Bahasa, 181.

$40 \mathrm{Ibid}, 135$.

${ }^{41}$ Tarigan, Pengajaran Gaya Bahasa, 56.

42 Ibid.

${ }^{43}$ Keraf, Diksi dan Gaya Bahasa, 134.

$44 \mathrm{lbid}$.

45 Ibid., 132.
Kurniawati bahwa eufemisme menjadi alternatif ungkapan lain dari ungkapan yang dianggap menghina, menyakiti hati sendiri, pendengar, atau pihak ketiga. ${ }^{46}$ Begitupun Wilpert dalam Kurniawati berpendapat bahwa ungkapan ini selain digunakan sebagai ungkapan retorik tetapi bisa digunakan juga untuk menghindari katakata yang tidak sopan, tidak sesuai dengan ajaran agama, nilai dan budaya sekitar, menutupi rasa malu, menghindari respon negatif, menunjukkan derajat pendidikan dari pembicara, dan tidak membuat ungkapan menjadi tidak indah untuk didengar. Contohnya menurut Tarigan yaitu "tunaaksara pengganti dari buta huruf." 47 Gaya bahasa disfemisme menurut Allan dan Buridge dalam Kurniawati merupakan ungkapan berupa hinaan yang dapat menyinggung perasaan orang lain, tidak mengenakkan, membicarakan tentang sesuatu yang memiliki nilai, derajat rendah. ${ }^{48}$ Bagi Zollner dalam Kurniawati gaya ini digunakan dengan tujuan untuk merendahkan, menghina sesuatu atau seseorang, mempertajam penghinaan, menunjukkan kekuasaan, menurunkan derajat lawan politik dari prestasi, sikap, ide pikiran, dan juga berfungsi sebagai ungkapan kemarahan. ${ }^{49}$

Gaya bahasa polisindenton merupakan Kata, frasa, klausa yang berurutan dihubungkan dengan kata sambung. ${ }^{50}$ Berikut contohnya, harga padi, dan jagung dan sayur-mayur sangat menggembirakan

\footnotetext{
${ }^{46}$ Heti Kurniawati, "Eufemisme dan Disfemisme Dalam Spiegel Online." LITERA: Jurnal Penelitian Bahasa, Sastra, dan Pengajarannya vol. 10, no. 1 (2011): 53.

${ }^{47}$ Tarigan, Pengajaran Gaya Bahasa, 126.

${ }^{48}$ Heti Kurniawati, "Eufimisme dan Difemisme Dalam Spiegel Online," 53.

49 Ibid.

50 Tarigan, Pengajaran Gaya Bahasa, 131.
} 
para petani tahun ini. ${ }^{51}$ Gaya bahasa anastrof merupakan perubahan susunan struktur kalimat dari SP menjadi PS pada satu kalimat. $^{52}$ Contohnya yaitu merantaulah dia ke negeri seberang tanpa meninggalkan apa-apa. ${ }^{53}$ Gaya bahasa asonansi merupakan perulangan bunyi vokal yang sama. ${ }^{54}$ Gaya bahasa ini dipakai untuk memberikan penekanan ataupun memberikan keindahan. Contohnya adalah jaga harga tahan raga. ${ }^{55}$ Gaya bahasa kiasan merupakan perbandingan antara dua hal yang mirip atau berbeda. ${ }^{56}$ Macammacamnya adalah persamaan atau simile, metafora, alegori, parabel dan fabel, personifikasi, alusi, eponim, epitet, sinekdoke, metonimia, antonomasia, hipalase, ironi, sinisme, dan sarkasme, satire, inuendo, antifrasis, dan paranomasia. Gaya bahasa metafora merupakan perbandingan yang implisit dalam satu kalimat. ${ }^{57}$ Menurut Poerwadarminta dalam Tarigan gaya bahasa tersebut merupakan penggunaan kata kiasan yang berdasarkan persamaan ataupun perbandingan. Contohnya, Nani jinak-jinak merpati. ${ }^{58}$ Gaya bahasa personifikasi merupakan benda mati yang memiliki sifat seperti manusia dalam satu kalimat. ${ }^{59}$ Menurut Dale dalam Tarigan bahwa personifikasi merupakan gaya bahasa yang memberikan penyifatan

\footnotetext{
$51 \mathrm{lbid}$.

52 Ibid., 130.

53 Ibid.

${ }^{54} \mathrm{Ibid}$.

$55 \mathrm{lbid}$.

56 Ibid., 129.

57 Ibid., 139-140.

$58 \mathrm{Ibid}$.

59 Ibid., 140.

$60 \mathrm{lbid}$.

$61 \mathrm{lbid}, 144$.

62 Ratna Sumarni, "31 Contoh Majas Satire Dalam Bahasa Indonesia," DosenBahasa.com, diakses 19
}

pribadi manusia ke benda mati maupun kepada gagasan. Berikut contohnya, hujan memandikan tanaman. ${ }^{60}$ Gaya bahasa satire yaitu ungkapan kritik penolakan atau menertawakan sesuatu agar ada perbaikan secara etis. ${ }^{61}$ Satire menurut Mulia dan Hidding dalam Sumarni adalah sajak kritik sindiran maupun langsung. Satire dipahami dalam satu wacana. ${ }^{62}$ Contohnya yaitu percuma saja aku berbicara hingga mulutku berbusa, kalau ternyata ucapanku ini tak didengar juga. ${ }^{63}$ Gaya bahasa sinekdoke pars pro toto adalah penggunaan sebagian untuk menyatakan keseluruhan. ${ }^{64}$ Contohnya adalah setiap tahun semakin banyak mulut yang harus diberi makan di Tanah Air kita ini. ${ }^{65}$

\section{Lagu dan Lirik Lagu}

Lagu berisi barisan penggunaan gaya bahasa yang memberikan efek keindahakan dan dibawakan dengan suara atau nada yang indah. ${ }^{66}$ Syair atau lirik lagu adalah puisi panjang atau pendek yang digunakan untuk mengungkapkan perasaan-perasaan yang dimiliki oleh seseorang. ${ }^{67}$ Menurut Herman J. Waluyo syair lagu merupakan salah satu sastra yang menggunakan bahasa sebagai media untuk menciptakan suatu imajinasi. ${ }^{68}$

Agustus, 2020. https://dosenbahasa.com/contohmajas-satire

63 Ibid.

$64 \mathrm{lbid}, 142$.

$65 \mathrm{Ibid}$.

66 Imam Mahdil Umami, "Analysis Wacana Penggunaan Gaya Bahasa Dalam Lirik Lagu-Lagu Ungu," Dinamika Bahasa dan Budaya vol. 3, no. 2 (2009): 201-217.

${ }^{67}$ Melani Budianta et al., Membaca Sastra: Pengantar Memahami Sastra Untuk Perguruan Tinggi (Magelang: Indonesia Tera, 2003), 182.

68 Herman J. Waluyo, Teori dan Apresiasi Puisi, (Jakarta: Erlangga, 1987), 8. 
Lirik lagu memiliki beberapa unsur, yaitu: pertama, bunyi memiliki peran dalam menciptakan suatu keindahan pada lirik. Adanya keselarasan bunyi mewakili makna rasa, batin, dan sikap dari penyair. Kedua, kata. Berdasarkan bentuk dan isinya, kata terbagi atas: (1) Lambang, yaitu kata yang maknanya sesuai dengan kamus leksikal; (2) utterance atau indice adalah makna kata yang sesuai dengan konteks; (3) simbol adalah kata yang mengandung makna konotatif. Ketiga, baris yaitu tempat tertulisnya kata, frasa, kalimat sebagai wujud ide yang disampaikan. Penataan baris menggunakan rima dan sajak atau disebut dengan enjambemen. Keempat, bait yaitu kumpulan baris-baris dalam lirik lagu dalam rangka mendukung satu pertamaan pokok pikiran. Kelima, tipografi yaitu aspek visual syair yang menciptakan makna dan susunan bentuk yang beraturan maupun tidak beraturan. ${ }^{69}$

\section{Lirik Lagu Sebujur Bangkai}

Badanpun tak berharga

sesaat ditinggal nyawa

anak istri tercinta

tak sudi lagi bersama

Secepatnya jasad dipendam

Secepatnya jasad dipendam

Karna tak lagi dibutuhkan

Diri yang semula dipuja

Kini bangkai tak berguna

Dari kamar yang indah

Kasur empuk tilam putih

Kini harus berpindah

$69 \mathrm{Ibid}$.

70 Alifia Astika, "Lirik Lagu 'Sebujur Bangkai' yang Dipopulerkan Oleh Rhoma Irama," sonora.id, diakses 26 Juli 2020,
Terkubur dalam perut bumi

Kalau selama ini

Diri berhiaskan

Emas intan permata

Bermandi cahaya

Tetapi kali ini

Di dalam kuburan

Gelap pekat mencekam

Tanpa seorang teman

Terputuslah

Pergaulan

Terbujurlah sendirian

Diri terbungkus kain kafan

Wajah dan tubuh indah

Yang dulu dipuja-puja

Kini tiada lagi

Orang sudi menyentuhnya Jadi santapan cacing tanah Jadi santapan cacing tanah Sampai yang tersisa kerangka

Begitulah suratan badan Ke bumi dikembalikan Kebanyakan manusia Terlena sehingga lupa Bahwa maut 'kan datang menjelang. ${ }^{70}$

https://www.sonora.id/amp/422253378/lirik-lagusebujur-bangkai-yang-dipopulerkan-oleh-rhomairama? page $=3$. 
Gaya Bahasa Berdasarkan Langsung Tidaknya Makna Pada Lirik Lagu Sebujur

\section{Bangkai}

Gaya bahasa hiperbol merupakan ungkapan yang berlebihan yang tidak sesuai dengan realitanya. ${ }^{71}$ Pada lirik ini terdapat beberapa penggunaan gaya bahasa hiperbol sebagai berikut: pada bait kedua, baris keempat yaitu "diri yang semula dipuja kini bangkai tak berguna" yang berarti selama ini biasanya tidak pernah puas melakukan perawatan wajah dan tubuh sampai mendapatkan pujian karena keelokan yang dimiliki berubah menjadi rusak, busuk, tidak bermanfaat apa-apa untuk sekitarnya. Pada kalimat tersebut terdapat pernyataan yang berlebihan pada sifat manusia selama hidup yang senantiasa tidak pernah puas dengan kondisi wajah dan tubuhnya. Termasuk gaya bahasa hiperbol. Pernyataan ini memberikan penekanan pada sifat manusia yang tidak pernah merasa cukup, selalu ingin lebih pada tubuh sampai lupa kalau pada akhirnya tubuh yang selama ini mendapat perawatan rusak, tidak akan berarti apa-apa (sia-sia) setelah meninggal.

Kemudian "diri berhiaskan, emas intan permata, bermandikan cahaya." Kalimat tersebut bermakna diri yang selalu dipenuhi dengan kemewahan perhiasan. Banyak dan mewahnya perhiasan yang dipakai seakan pribadi mandi dengan cahaya. Pernyataan tersebut terdapat pernyataan yang berlebihan pada ungkapan "Diri bermandi cahaya", sebab realitanya diri atau manusia mandi bukan dengan cahaya, ungkapan bermandi cahaya hanya untuk melebih-

${ }^{71}$ Gorys Keraf, Diksi dan Gaya Bahasa, 135.

72 lbid.

73 Ibid., 134. lebihkan kondisi kemewahan dan banyaknya perhiasan yang digunakan. Sehingga termasuk gaya bahasa hiperbol. ${ }^{72}$ Dengan adanya ungkapan yang berlebihan tersebut membuat detail gambaran kemewahan dan banyaknya perhiasan yang dikenakan pada diri atau manusia.

Gaya bahasa perifrasa merupakan penggunaan banyak kata yang bisa diganti dengan satu kata. ${ }^{73}$ Dalam studi lirik ini terdapat penggunaan perifrasa pada bait pertama baris kedua yaitu "sesaat ditinggal nyawa" yang berarti sudah meninggal. Terdapat penggunaan kata yang lebih banyak hanya untuk menyatakan meninggal. Termasuk gaya bahasa perifrasa. ${ }^{74}$ Ungkapan pada lirik tersebut terdengar lebih sopan, tidak terlalu kasar, saat mengungkapkan kondisi sudah mati, meninggal. Selain itu memberikan efek yang indah pada lirik, terdengar lebih puitis dengan menggunakan kalimat "sesaat ditinggal nyawa."

Gaya bahasa eufemisme adalah penggunaan ungkapan pengganti yang tidak menyakiti hati, ataupun merugikan. ${ }^{75}$ Adanya penggunaan gaya bahasa eufemisme pada lirik Sebujur Bangkai pada bait kedua baris pertama sampai dua yaitu "secepatnya jasad dipendam." Dalam kalimat tersebut terdapat penggunaan gaya bahasa yang menggunakan kata halus pada kata "jasad" untuk menggantikan kata "mayat". Kata yang digunakan terdengar halus, sopan dari pada menggunakan kata "mayat" yang terdengar lebih keras, kasar oleh pendengar. Sehingga termasuk gaya bahasa eufimisme. ${ }^{76}$ Adapun efek lain dari

\footnotetext{
${ }^{74}$ Ibid.

75 Ibid., 132.

76 Ibid.
} 
penggunaan gaya bahasa tersebut untuk memberikan efek keindahan, kebaruan pada lirik lagu karena menggunakan kata puitis yang jarang didengar dibanding menggunakan kata lain yang sering didengar berupa bangkai.

Selain itu penggunaan gaya bahasa eufemisme terdapat pada penggunaan kata "badan" pada bait pertama baris pertama, "jasad" pada bait kedua baris pertama sampai kedua, "tubuh" pada bait ketujuh baris pertama dan "diri" pada bait kedua baris pertama, bait keempat baris ketiga sebagai pengganti dari kata bangkai saat menjelaskan di awal lirik lagu, dan saat menjelaskan perbandingan di awal dengan kondisi atau situasi yang lebih baik. Tentu hal ini tidak membuat sakit hati, dirasa kasar oleh pendengar sebagai pihak kedua. Selain itu dengan adanya ragam kata pada lirik tersebut dapat membuat lirik menjadi indah dan pendengar tidak bosan, atau monoton karena mendengarkan kata yang sama pada semua lirik lagu.

Disfemisme menurut Allan dan Buridge dalam Kurniawati merupakan ungkapan berupa hinaan yang dapat menyinggung perasaan orang lain, tidak mengenakkan, membicarakan tentang sesuatu yang memiliki nilai, derajat rendah. ${ }^{77}$ Penggunaan kata "bangkai" pada bait ketiga baris pertama merupakan penggunaan gaya bahasa yang tidak enak didengar untuk membicarakan kondisi tubuh yang nilainya sudah rendah (mayat). Kata ini digunakan saat menjelaskan perbandingan kondisi atau situasi badan atau tubuh yang lebih buruk dibanding situasi sebelumnya.

77 Heti Kurniawati, "Eufimisme dan Difemisme Dalam Spiegel Online," 53.

78 Gorys Keraf, Diksi dan Gaya Bahasa, 131.
Gaya bahasa polisindenton merupakan kata, frasa, klausa yang berurutan dihubungkan dengan kata sambung. ${ }^{78}$ Bait ketujuh baris pertama yaitu "wajah dan tubuh indah" terdapat penggunaan kata "dan" sebagai kata sambung untuk katakata yang sejajar sehingga termasuk gaya bahasa polisindenton. ${ }^{79}$ Kata sambung yang digunakan pada lirik ini untuk menghubungkan kedua kata yang memiliki kesamaan nilai. Kata "wajah" dan "tubuh" yang keduanya sama-sama indah. Dengan adanya penggunaan gaya bahasa tersebut dapat mempersingkat penyampaian pesan, tetapi efektif dan efisien. Maksud yang disampaikan mengenai kesamaan nilai pada kedua aspek yang dijelaskan (wajah dan tubuh) tetap sampai dan bisa dipahami.

Gaya bahasa anastrof merupakan perubahan susunan struktur kalimat dari SP menjadi PS pada satu kalimat. ${ }^{80}$ Pada kalimat "terputuslah pergaulan" di bait keenam baris pertama dan kedua terdapat perubahan posisi struktur kalimat dari kata pergaulan selaku subjek dan "terputuslah" selaku predikat berubah posisi menjadi "terputuslah pergaulan." Termasuk gaya bahasa anastrof. ${ }^{81}$ Pada kalimat tersebut penggunaan verba kata "terputuslah" sebagai predikat, posisinya ada sebelum kata "pergaulan" yang merupakan nomina sebagai subjek dapat memberikan efek keindahan pada lirik lagu. Kalimat pada lirik tersebut terdengar tidak seperti kalimat yang biasanya digunakan SP yaitu "pergaulan terputus" atau dengan menggunakan kalimat lain seperti "tidak ada teman" yang terdengar biasa saja, ada

\footnotetext{
79 lbid.

80 Ibid., 130.

81 Ibid.
} 
kebaruan yang membuat pendengar tertarik untuk mendengarkan kalimat pada lirik tersebut.

Gaya bahasa asonansi merupakan perulangan bunyi vokal yang sama. ${ }^{82}$ Dalam lirik ini terdapat penggunaan gaya bahasa asonansi. Berikut beberapa kalimat yang menggunakan gaya bahasa asonansi:

Bait pertama baris pertama yaitu "tak sudi lagi bersama" yang bermakna tidak ada satu orang pun yang mau menemani di dalam kuburan. Terdapat bunyi vokal yang sama "i" pada kata "sudi" dan "lagi" maka termasuk gaya bahasa asonansi. ${ }^{83}$ Pengulangan vokal tersebut untuk menekankan keengganan anggota keluarga yang selama ini dicintai dan selalu bersama menjadi tidak mau tinggal bersama lagi (tinggal di liang kubur).

Kemudian bait pertama baris pertama hingga keempat, "badanpun tak berharga, sesaat ditinggal nyawa, anak istri tercinta, tak sudi lagi bersama" terdapat bunyi vokal yang sama a-a-a-a maka termasuk gaya bahasa asonansi. ${ }^{84}$ perulangan vokal a yang sama di akhir tiap kalimat sebanyak empat kali dalam satu bait yang sama untuk memberikan efek keindahan pada lirik dalam satu bait sehingga akan terdengar indah oleh pendengar.

Lalu bait keempat baris pertama sampai kedua, "terkubur dalam perut bumi, kalau selama ini." Pada lirik tersebut terdapat penggunaan bunyi vokal yang sama $i$ pada kata "bumi" dan "ini". Termasuk gaya bahasa asonansi. ${ }^{85}$ Perulangan bunyi vokal yang sama di akhir kalimat dalam satu bait

82 Ibid.

83 Ibid.

84 lbid.

85 Ibid. sebanyak 2 kali untuk memberikan efek keindahan pada lirik lagu akibat kesamaan bunyi.

Selanjutnya pada bait keempat baris keempat dan kelima yaitu "emas intan permata, bermandi cahaya" terdapat penggunaan gaya bahasa yang mengandung bunyi vokal yang sama yaitu aa pada kata "permata" dan "cahaya". Termasuk penggunaan gaya bahasa asonansi. ${ }^{86}$ Perulangan bunyi vokal yang sama di akhir kalimat dalam satu bait sebanyak dua kali tersebut untuk menekankan kemewahan perhiasan.

Lalu pada bait ketujuh baris ketiga yaitu "kini tiada lagi" terdapat penggunaan bunyi vokal i-i yang sama. Termasuk gaya bahasa asonansi. Perulangan bunyi vokal yang sama dalam satu kalimat sebanyak dua kali untuk memberikan efek keindahan pada lirik dibanding menggunakan ungkapan selainnya seperti kata sekarang.

Dan bait kesembilan baris pertama dan kedua, "kebanyakan manusia, terlena sehingga lupa" terdapat bunyi vokal yang sama yaitu $a$ tiap akhir kalimat dalam satu bait sebanyak dua kali. Sehingga termasuk gaya bahasa asonansi. ${ }^{87}$ Perulangan tersebut memberikan efek keindahan pada lirik lagu.

Gaya bahasa aliterasi yaitu adanya penggunaan bunyi konsonan yang sama yang ditunjukkan untuk memberikan efek keindahan atau penekanan. ${ }^{88}$ Berikut kalimat pada lirik lagu yang menggunakan gaya bahasa aliterasi: Bait ketiga baris

\footnotetext{
86 Ibid.

87 Ibid.

88. Ibid., 181.
} 
kedua dan keempat yaitu "dari kamar yang indah, kini harus berpindah." Terdapat bunyi konsonan yang sama yaitu ah maka termasuk gaya bahasa aliterasi. ${ }^{89}$ Perulangan bunyi konsonan yang sama di akhir tiap kalimat dalam satu bait lirik lagu sebanyak dua kali untuk memberikan efek keindahan pada lirik, pendengar menikmati lagu tersebut, tidak menggunakan kata biasa seperti "sekarang tidak tidur di kamar yang bagus lagi tetapi tidur di liang lahat."

Begitupun dengan kalimat "diri berhiaskan" pada bait keempat baris ketiga, "di dalam kuburan" bait kelima baris kedua, "tanpa seorang teman" bait yang sama baris keempat, "terputuslah pergaulan" bait keenam baris kedua, "terbujurlah sendirian" bait yang sama baris ketiga, "terbungkus kain kafan" di baris keempat terdapat penggunaan konsonan $n$ yang sama, termasuk gaya bahasa aliterasi. ${ }^{90}$ Perulangan konsonan yang sama pada tiap akhir kata, kalimat dalam satu bait sebanyak lima kali untuk memberikan efek keindahan pada bait lirik lagu.

Selain itu pada bait keenam baris pertama sampai ketiga, "terputuslah pergaulan," "terbujurlah sendirian" terdapat penggunaan akhiran konsonan yang sama yaitu $h$ sehingga termasuk gaya bahasa aliterasi. ${ }^{91}$ Perulangan bunyi konsonan yang sama tiap akhir kalimat dalam satu bait sebanyak dua kali untuk memberikan efek penekanan kondisi yang terjadi saat ada di dalam kubur yang benar-benar sendiri, tidak ada yang menemani.

89 lbid., 130.

$90 \mathrm{lbid}$.

${ }^{91}$ lbid.
Lalu bait ketujuh baris pertama, kalimat "wajah dan tubuh indah" terdapat penggunaan bunyi konsonan $h-h$ yang sama. Termasuk gaya bahasa aliterasi. Perulangan bunyi konsonan yang sama di akhir kata dalam satu kalimat sebanyak dua kali untuk memberikan efek keindahan pada lirik daripada menggunakan ungkapan kata lain seperti "wajah dan tubuh yang baik," bagus, atau selainnya.

Bait kedelapan baris keempat dengan bait kesembilan baris pertama, "begitulah suratan badan, ke bumi dikembalikan" terdapat bunyi konsonan yang sama yaitu $n$ sehingga termasuk gaya bahasa aliterasi. ${ }^{92}$ Penggunaan bunyi konsonan yang sama di akhir tiap kalimat dalam satu bait sebanyak dua kali memberikan efek keindahan pada lirik karena terdengar seirama di akhir tiap kalimat dalam bait.

Dan bait kesembilan baris keempat, "bahwa maut kan datang menjelang" terdapat bunyi konsonan yang sama yaitu ang sehingga termasuk gaya bahasa aliterasi. ${ }^{93}$ Adanya perulangan bunyi konsonan yang sama di tiap akhir kalimat dalam satu bait yang sama sebanyak dua kali memberikan efek keindahan pada lirik lagu.

Gaya bahasa metafora merupakan perbandingan yang implisit dalam satu kalimat. ${ }^{94}$ Pada lirik terdapat kalimat "badanpun tak berharga" di bait pertama baris pertama yang menunjukkan badan manusia sudah tidak memiliki manfaat apaapa, sudah menjadi mayat terdapat penggunaan perbandingan implisit yang digunakan yaitu "badanpun (seperti) tak berharga." Perbandingan tersebut untuk

\footnotetext{
92 Ibid.

93 Ibid.

94 Ibid., 139-140.
} 
membandingkan secara implisit kondisi tubuh manusia yang sebelumnya berharga (berfungsi) menjadi tidak berharga (berfungsi). Dapat dikatakan gaya bahasa tersebut digunakan untuk membandingkan secara implisit nilai tubuh. Termasuk gaya bahasa metafora. ${ }^{95}$

Gaya bahasa personifikasi merupakan benda mati yang memiliki sifat seperti manusia dalam satu kalimat. ${ }^{96}$ Kalimat "terkubur dalam perut bumi" di bait keempat baris pertama, termasuk penyifatan manusia pada bumi yang memiliki bagian perut maka terdapat penggunaan gaya bahasa personifikasi. ${ }^{97}$ Penyifatan tersebut dalam rangka menjelaskan kualitas bagian bumi yang sama dengan kualitas tubuh manusia. Bumi dianggap memiliki bagian tubuh yang sama seperti manusia. Hal ini dapat memberikan efek keindahan pada lirik sebab tidak menggunakan ungkapan yang biasa didengar seperti "terkubur di dalam tanah".

Gaya bahasa satire yaitu ungkapan kritik penolakan atau menertawakan sesuatu agar ada perbaikan secara etis. ${ }^{98}$ Kalimat "diri yang semula dipuja, kini bangkai tak berguna, dari kamar yang indah, kasur empuk tilam putih, kini harus berpindah terkubur dalam perut bumi" pada bait kedua baris keempat sampai bait keempat baris pertama, terdapat penggunaan sindiran pada kesadaran manusia tentang fisik, dan fasilitas yang dimiliki selama ini akan berubah setelah meninggal. Termasuk gaya bahasa satire. Sindiran ini tujuannya agar pendengar sebagai manusia yang

\footnotetext{
95 Ibid., 139.

96 Ibid., 140.

97 lbid.

98 Ibid., 144.
}

masih hidup tersadarkan, teringatkan bahwa akan ada perubahan situasi yang akan dialami setelah meninggal, jangan melupakan tentang perubahan itu hanya karena hidup dirasa sudah nyaman, aman, dan ada dalam posisi kehidupan yang baik.

Gaya bahasa sinekdoke pars pro toto adalah penggunaan sebagian untuk menyatakan keseluruhan. ${ }^{99}$ Bait pertama baris ketiga yaitu "anak istri tercinta." Anak dan istri merupakan bagian dari keluarga yang sangat dicintai, terdapat penyebutan sebagian anggota keluarga untuk keseluruhan penyebutan "keluarga". Penyebutan tersebut detail terhadap tiap status anggota keluarga untuk menggantikan kata keluarga yang benarbenar dicintai. Sehingga termasuk gaya bahasa sinekdoke pars pro toto. ${ }^{100}$ Dengan mendetailkan penggunaan tiap status keluarga maka ada penekanan terhadap apa yang dicintai dan akan tersampaikan secara jelas siapa saja yang memang benarbenar dicintai oleh manusia ketika sudah berkeluarga.

\section{Pesan Dakwah Pada Lirik Lagu Sebujur Bangkai}

Tarhib dan indzar yaitu menyampaikan hal yang menakutkan, menyedihkan, maupun siksaan. ${ }^{101}$ Pada bait pertama lirik lagu terdapat pesan dakwah tarhib dan indzar. Bait tersebut menjelaskan kondisi yang begitu menyedihkan ketika manusia sudah dicabut nyawanya tubuhnya yang biasanya bernapas, bergerak untuk melakukan

\footnotetext{
99 Ibid., 142.

100 Islamawati, "Ekspresi Pesan Dakwah Dalam SyairSyair Lagu Jefri Al-Bukhori" 10-11. 101 lbid.
} 
kehendak hanya bisa terbujur kaku, tidak bisa berfungsi apa-apa bahkan dalam hitungan waktu semakin membusuk. Dalam kondisi tubuh seperti itu ditambah keluarga yang biasanya mau menemani di manapun dan kapanpun menjadi enggan, tidak ada yang mau hidup dengan tubuh yang menjadi bangkai, menemani untuk tinggal di dalam tanah. Dalam kondisi tersebut tentu siapapun akan mengalami rasa sedih saat keluarga yang dicintai ditinggalkan, tidak bisa hidup bersama lagi, mereka juga enggan hidup bersama di dalam kuburan, dan tubuh yang tidak bermakna apa-apa lagi untuk diri bahkan orang lain. Semua pesan tentang situasi dan kondisi yang menyedihkan itu tersampaikan dalam bait pertama lirik lagu. Sehingga pada bait pertama tersebut terdapat penggunaan pesan dakwah tarhib dan indzar.

Lalu pada bait selanjutnya hingga baris pertama di bait ketiga terdapat ungkapan yang menyatakan bahwa jasad manusia harus segera dikuburkan sebab sudah mulai membusuk saat meninggal. Jika dihubungkan dengan bait sebelumnya yang menjelaskan tentang situasi keluarga yang tidak mau tinggal bersama, sendirian di dalam kuburan, ditambah tubuh sudah mulai membusuk sehingga harus dijauhkan dari sekitar seakan dibuang (dikubur). Pesan disampaikan dengan menyedihkan dalam menjelaskan detail saat terjadi kematian pada manusia. Sehingga pada bait lirik tersebut terdapat penyampaian pesan dakwah tarhib dan indzar.

Kemudian pada bait ketiga baris kedua hingga bait keenam yang menjelaskan perbandingan di awal sebelum dan setelah meninggal khususnya fasilitas dan kepemilikan selama hidup. Mulai dari kamar yang mewah dan nyaman, perhiasan, teman, atau sahabat semua hilang, berubah seketika setelah meninggal. Tidur yang biasanya empuk di kasur berubah jadi tidur di tanah, gelap tidak ada cahaya, emas yang biasanya dikenakan banyak menjadi tidak dipakai lagi, teman atau sahabat yang biasanya ada menemani menjadi sendirian dengan dibalut kain kafan. Lewat pendetailan pesan mengenai perbandingan sebelum dan sesudah kematian tersebut nampak terasa begitu menakutkan. Tentu tidak akan biasa orang yang selalu dikelilingi oleh keramaian orang terdekat dan kemewahan tiba-tiba berubah, hilang seketika. Sehingga masih termasuk pesan dakwah tarhib dan indzar.

Kemudian pada bait ketujuh yang menjelaskan mengenai perbandingan kondisi fisik dan respon lingkungan saat sebelum meninggal dan setelah meninggal. Sebelum meninggal, fisik yang begitu dirawat sampai indah dan banyak lingkungan yang suka, tertarik dengan fisik yang dimiliki semua berubah saat sudah meninggal. Kondisi fisik sudah membusuk, tentu perawatan yang selama ini dilakukan menjadi sia-sia, lingkungan sekitarpun banyak yang menjauh karena sudah membusuk. Tidak ada yang mau menyentuh tubuh, sebab baunya pun sudah tidak enak karena tubuh sudah membusuk. Lewat perincian tersebut pesan disampaikan dengan cara yang memiriskan, menyedihkan. Pada bait tersebut masih menggunakan tarhib dan indzar.

Selanjutnya pada bait kedelapan yang menjelaskan tentang kondisi tubuh manusia yang sudah terurai oleh binatang pengurai dalam tanah saat terjadi pembusukan sampai yang tersisa tulang saja. Binatang 
pengurai seperti cacing yang begitu menjijikan, tidak menakutkan berubah menjadi hewan yang menakutkan karena bisa menggerogoti tubuh, daging, lemak dan semua komponen yang ada pada tubuh manusia hingga hanya menyisakan tulang. Tentu saja penjelasan tersebut semakin mendetailkan tentang kondisi setelah meninggal dan begitu menakutkan. Hal itu bisa terpahami karena penyampaian pesan dakwah yang menakutkan. Sehingga pada bait ini pun menggunakan pesan dakwah tarhib dan indzar.

Tadzkir dan tanbih adalah penyampaian dakwah dengan cara mengingatkan kembali akan nilai-nilai yang diamalkan,dan pengetahuan yang dimiliki. ${ }^{102}$ Pada bait kedelapan, baris keempat hingga bait kesembilan, baris pertama yang menyatakan tentang kepastian takdir kematian. Bait-bait tersebut jika dihubungkan dengan bait sebelumnya dari bait pertama hingga bait kedelapan baris ketiga, bait ini berisi penyampaian pesan yang mengingatkan pada pengetahuan tentang kepastian takdir kematian pada setiap manusia.

Taklim dan tarbiyah adalah gaya penyampaian dakwah dengan mendidik, menasihati agar memiliki keimanan dan muamalah yang sesuai dengan nilai-nilai Islam. Sedangkan qoshos dan riwayar merupakan penyampaian dakwah dengan jalan cerita, baik sejarah, masa lampau, dan selainnya. ${ }^{103}$ Bait kesembilan baris kedua hingga akhir jika dihubungkan dengan bait sebelumnya yang banyak detail kondisi, situasi setelah meninggal maka bait kesembilan ini merupakan bait dan baris

102 Islamawati, "Ekspresi Pesan Dakwah Dalam SyairSyair Lagu Jefri Al-Bukhori" 10-11. yang memberikan nasihat dalam bentuk bilhikmah lewat pengisahan bagaimana orang selama ini sudah banyak yang terlena dengan kenikmatan, kenyamanan, dan kemewahan di dunia hingga lupa dengan kematian yang sebenarnya begitu menakutkan, dan menyedihkan. Pesan "jangan sampai yang mendengarkan lagu juga sampai melupakan tentang kematian" di bait kesembilan. Hal ini termasuk penyampaian dakwah taklim dan tarbiyah berkolaborasi dengan qoshos dan riwayar.

\section{Kesimpulan}

Temuan studi berdasarkan pembahasan yang dilakukan penulis tentang gaya bahasa yang digunakan pada lirik lagu sebujur bangkai antara lain, Pertama hiperbol, ditemukan pada bait kedua baris keempat, dan bait keempat baris ketiga hingga akhir. Kedua gaya bahasa perifrasa ditemukan pada bait pertama baris kedua. Ketiga eufemisme pada bait kedua baris pertama sampai kedua. Lalu, pada penggunaan kata badan pada bait pertama baris pertama, jasad pada bait kedua baris pertama sampai kedua, tubuh pada bait ketujuh baris pertama dan diri pada bait kedua baris pertama, dan bait ke empat baris ketiga. Keempat disfemisme ditemukan pada kata bangkai di bait ketiga baris pertama. Kelima majas polisindenton ada pada bait ketujuh baris pertama. Keenam anastrof ditemukan pada bait keenam baris pertama dan kedua. Ketujuh majas asonansi pada bait pertama baris pertama, bait pertama baris pertama hingga keempat, bait keempat baris pertama sampai dua, bait keempat baris keempat dan kelima, bait kelima baris kedua, dan keempat, bait keenam baris

103 Ibid. 
kedua, ketiga, dan keempat. Lalu pada bait ketujuh baris ketiga, dan bait kesembilan baris pertama dan kedua. Kedelapan gaya bahasa aliterasi ada pada bait ketiga baris kedua dan keempat, bait keempat baris ketiga, bait keenam baris pertama sampai ketiga, bait ketujuh baris pertama, bait kedelapan baris keempat dengan bait kesembilan baris pertama, dan bait kesembilan baris keempat. Kesembilan majas metafora pada bait pertama baris pertama. Kesepuluh gaya personifikasi ada di bait keempat baris pertama. Kesebelas majas satire pada bait kedua baris keempat sampai bait keempat baris pertama. Keduabelas gaya bahasa sinekdoke pars pro toto ada di bait pertama baris ketiga.

Sedangkan berdasarkan analisis pesan dakwah, lagu Sebujur Bangkai mengandung beberapa pesan dakwah di antaranya pesan tarhib dan indzar terdapat pada bait pertama hingga bait kedelapan baris ketiga. Kemudian pesan tadzkir dan tanbih pada bait kedelapan baris keempat hingga bait kesembilan baris pertama. Lalu kolaborasi antara pesan dakwah taklim dan tarbiyah dengan qoshos dan riwayar pada bait pertama hingga bait kekesembilan yang dihubungkan dengan bait kesembilan baris kedua.
Dari kajian yang telah dilakukan ini, menyarankan agar para aktivis dakwah yang hendak berdakwah bisa menggunakan beragam jenis gaya bahasa langsung tidaknya makna baik retorik maupun kiasan untuk menegaskan pesan yang disampaikan, mendetailkan pesan dengan ungkapan yang indah, sampai menasihati dengan cara yang halus lewat sindiran yang baik sehingga pendengar selaku mad'uw dapat memberikan feedback yang positif. Selain itu calon dai pun dalam menyampaikan pesan dakwahnya lewat lirik lagu dapat menggunakan beragam bentuk pesan dakwah. Bisa menggunakan salah satu bentuk ataupun mengolaborasikan beragam jenis bentuk dalam satu lirik lagu. Hal ini dapat menambahkan kekuatan emosi yang disampaikan pada pendengar, dan saat sudah klimaks emosi yang disampaikan barulah di akhir diberikan hikmah maupun masukan nasihat yang semestinya dilakukan. Sehingga pesan dakwah sejak awal sudah dinikmati dan tanpa sadar sudah masuk dalam pikiran dan perasaan pendengar.

\section{Bibliografi}

Achsani, Ferdian dan Siti Aminah Nur Laila. "Pesan Dakwah Dalam Lirik Lagu Menyambut Lebaran Karya Pendhoza." Nalar: Jurnal Peradaban dan Pemikiran Islam vol. 3, no. 2 (2019): 122-133. DOI: 10.23971/njppi.v3i2.1435

Anjani, Eka. "Gaya Bahasa K.H. Zainuddin M.Z. Dalam Ceramah Isra Mikraj di Tanggerang Selatan." Inteleksia: Jurnal Pengembangan IImu Dakwah vol. 01, no. 1 (2019): 161-185. http://inteleksia.stidalhadid.ac.id/index.php/inteleksia/article/view/17 
Astika, Alifia. "Lirik Lagu 'Sebujur Bangkai' yang Dipopulerkan Oleh Rhoma Irama." sonora.id. Accessed July, 2020. https://www.sonora.id/amp/422253378/lirik-lagu-sebujur-bangkaiyang-dipopulerkan-oleh-rhoma-irama?page=3.

Aziz, Jum'ah Amin Abdul. Fiqih Dakwah Prinsip dan Kaidah Asasi Dakwah Islam. Surabaya: Era Intermedia, 2005.

Aziz, Moh. Ali. Ilmu Dakwah. Jakarta: Kencana Prenada Media, 2004.

Budianta, Melani, Ida Sundari Husen, Manneke Budiman dan Ibnu Wahyudi. Membaca Sastra: Pengantar Memahami Sastra Untuk Perguruan Tinggi. Magelang: Indonesia Tera, 2003.

Dimyati, Farid. "Kekuatan Musik dalam Dakwah Islam." nuonline. Accessed July 12, 2019. www.nu.or.id/post/read/78651/kekuatan-musik-dalam-dakwah-islam.

Fathoni, Hanif. "Gaya Bahasa Dalam Syair "Al-i'tiraf" Karya Abu Nuwas: Sebuah Analisis Stilistik." At-Ta'dib: Journal of Pesantren Education vol. 7, no. 2 (2012): 205-224. DOI: 10.21111/attadib.v7i2.72.

Harahap, Sulaiman. "Rhoma Irama: Sang Penghulu Mempelai Dangdut dan Dakwah." $\begin{array}{llll}\text { Republika.co.id. Accessed } & \text { July }\end{array}$ https://www.republika.co.id/berita/nasional/umum/15/08/05/senggang/musik/12/04/1 6/m2kji3-rhoma-irama-sang-penghulu-mempelai-dangdut-dan-dakwah.

Hasbullah, Moeflich. Islam dan Transformasi Masyarakat Nusantara. Depok: Kencana Prenada Media, 2017.

Islamawati, Endang. "Ekspresi Pesan Dakwah Dalam Syair-Syair Lagu Jefri Al Bukhori (Analisis Terhadap Album 'Lahir Kembali')." Skripsi, Institut Agama Islam Negeri Walisongo Semarang, 2008.

Jafar, Iftitah dan Mudzhira Nur Amrullah. "Bentuk-Bentuk Pesan Dakwah Dalam Kajian AlQur'an." Jurnal Komunikasi Islam vol. 08, no. 01 (2018): 41-66. http://jki.uinsby.ac.id/index.php/jki/article/view/148

Keraf, Gorys. Diksi dan Gaya Bahasa. Jakarta: Gramedia Pustaka Utama, 1984.

Kurniawati, Heti. "Eufemisme dan Disfemisme Dalam Spiegel Online." LITERA: Jurnal Penelitian Bahasa, Sastra, dan Pengajarannya vol. 10, no. 1 (2011): 51-63. DOI: 10.21831/Itr.v10i1.1172.

Nadzifah, Faizatun. "Pesan Dakwah Dosen Dakwah STAIN Kudus dalam Surat Kabar Harian Radar Kudus." AT-TABSYIR: Jurnal Komunikasi Penyiaran Islam vol. 01, no. 01 (2015): 109-126. https://journal.iainkudus.ac.id/index.php/komunikasi/article/view/449

Permana, Restiawan. "Strategi Komunikasi Dakwah Band Wali dalam Lagu Cari Berkah." Jurnal Komunikasi Islam vol. 03, no. 01 (2013): 121-136. http://jki.uinsby.ac.id/index.php/iki/article/view/17

Rahmat, Sujud Puji Nur, G.R. Lono Lastoro Simatupang, dan Harsawibawa Albertus. "Musik Metal dan Nilai Religius Islam Tinjauan Estetika Musik Bermuatan Islami Dalam Penampilan Purgatory." Resital: Jurnal Seni Pertunjukan vol. 18, no. 03 (2017):133-143. DOI: 10.24821/resital.v18i3.3338.

"Sebujur Bangkai." Video Youtube. 4:08. Dikirim oleh "Falcon," Juni 17, 2013. https://www.youtube.com/watch?v=PdXljK7LRKU.

Salam, Abdus. "Mengkaji Syair Lir-llir Karya Sunan Kalijaga" alif.id. Accessed July 25, 2020. https://alif.id/read/abdus-salam/mengkaji-syair-lir-ilir-karya-sunan-kalijaga-b221759p/. 
Shihab, M. Quraish. "Membumikan" Al Quran: Fungsi dan Peran Wahyu Dalam Kehidupan Masyarakat. Bandung: Mizan, 1993.

Siswono, S.S. Teori dan Praktik: Diksi, Gaya Bahasa, dan Pencitraan. Yogyakarta: Deepublish, 2012.

Sugiyono. Metode Penelitian Kuantitatif, Kualitatif, dan R\&D. Bandung: Alfabeta, 2014.

Sujatmiko, Bagus dan Ropingi el Ishaq. "Pesan Dakwah Dalam Lagu 'Bila Tiba'” Jurnal Komunika vol. 09, no. 02 (2015): 181-195. DOI: 10.24090/komunika.v9i2.848.

Sumarni, Ratna. "31 Contoh Majas Satire Dalam Bahasa Indonesia." DosenBahasa.com. Accessed August 19, 2020. https://dosenbahasa.com/contoh-majas-satire.

Tarigan, Henry Guntur. Pengajaran Gaya Bahasa. Bandung: Angkasa, 2013.

Qolbi, Nur dan S. Dian Adryanto. "Ustadz Syam Minta Maaf ke MUI, Ceramahnya Diprotes Publik." TEMPO.CO. Modified July, 2017. https://nasional.tempo.co/read/893193/ustadzsyam-minta-maaf-ke-mui-ceramahnya-diprotes-publik.

Umam, Khairul dan Kamalludin. "Analisis Nilai-Nilai Pendidikan Islam Dalam Lirik Lagu Rhoma Irama" Fikrah: Journal of Islamic Education vol. 02, no. 1 (2018): 13-21. DOI: 10.32507/fikrah.v2i1.264.

Umami, Imam Mahdil. "Analysis Wacana Penggunaan Gaya Bahasa Dalam Lirik Lagu-Lagu Ungu: Kajian Stilistika" Dinamika Bahasa dan Budaya vol. 3, no. 2 (2009): 201-217. https://www.unisbank.ac.id/ojs/index.php/fbib1/article/view/451.

Waluyo, Herman J. Teori dan Apresiasi Puisi. Jakarta: Erlangga, 1987.

Wardana, Yesaya Whisnu. "Perkembangan Musik Dangdut dan Sensualitas Goyangan Para Biduannya." Compusiciannews.com. Accessed July, 2020. https://compusiciannews.com/2020/07/08/perkembangan-musik-dangdut-dansensualitas-goyangan-para-biduannya/.

Wibisono, Nuran. "Dangdut Koplo, Puncak Evolusi Dangdut." tirto.id. Accessed August, 2020. https://tirto.id/dangdut-koplo-puncak-evolusi-dangdut-cACw.

Yantos. "Analisis Pesan-Pesan Dakwah Dalam Syair-Syair Lagu Opick." Jurnal Dakwah Risalah vol. 24, no. 2 (2013):16-27. http://ejournal.uin-suska.ac.id/index.php/risalah/article/view/20 Yusuf, Ali Anwar. Islam Dan Sains Modern: Sentuhan Islam Terhadap Berbagai Disiplin IImu. Bandung: Pustaka Setia, 2006. 
Mega Cynthia

126| INTELEKSIA - Jurnal Pengembangan Ilmu Dakwah 